Article

\title{
Determining a Welfare Prioritization for Horses Using a Delphi Method
}

\author{
Fiona C. Rioja-Lang ${ }^{1}$, Melanie Connor ${ }^{1}$, Heather Bacon ${ }^{1}{ }^{\mathbb{D}}$ and Cathy M. Dwyer ${ }^{1,2, *}$ \\ 1 Royal (Dick) School of Veterinary Studies, University of Edinburgh, Edinburgh EH25 9RG, UK; \\ Fiona.lang@ed.ac.uk (F.C.R.-L.); melanie.connor@ed.ac.uk (M.C.); Heather.Bacon@ed.ac.uk (H.B.) \\ 2 Animal Behaviour and Welfare, Department of Animal and Veterainry Sciences, Central Faculty, \\ Scotland's Rural College (SRUC), Edinburgh EH9 3JG, UK \\ * Correspondence: cathy.dwyer@ed.ac.uk; Tel.: +44-131-651-7446
}

Received: 16 March 2020; Accepted: 7 April 2020; Published: 9 April 2020

Simple Summary: Horses are used for a wide range of different purposes and may be vulnerable to a large number of different welfare issues, some of which are unique to equines, such as responses to being ridden or trained. Compared to farmed livestock, their welfare has received less attention, but concern for their welfare is increasing. Welfare issues can arise from the environments in which animals are kept, how they are treated by their human caregivers and their health. To determine which of the issues are most important and may need the greatest attention in terms of research effort or owner education, we used a process of eliciting expert opinion. Through a series of surveys and ranking of issues, we determined that, in the opinion of equine experts, the most important issues for horses were poor disease prevention, issues arising when old or sick horses are not promptly euthanized, lack of owner knowledge of welfare needs of horses, fear and stress involved in horse use, inability of owners to recognize pain behaviour, obesity and inadequate feeding practices. Prioritizing different welfare issues can help to focus attention on the most pressing or severe issues causing the greatest amount of suffering.

\begin{abstract}
Equine welfare issues are receiving increasing attention in the UK, but welfare problems can arise from a wide range of causes. In order to identify the most important welfare concerns for horses, we used a Delphi method with 19 equine welfare experts. An initial list of 84 equine welfare issues was generated using an online discussion board and NVivo thematic analysis. Subsequently, experts ranked these welfare issues for perceived prevalence, severity and duration of suffering associated with each issue on a 6-point Likert scale. All issues with a mean score of 3 or above $(n=37)$ were included in subsequent rounds. Finally, a subset of experts attended a two-day workshop to determine the final priority list of welfare issues. The welfare issues perceived to be most prevalent were lack of biosecurity, delayed euthanasia, lack of owner knowledge of equine welfare needs, fear and stress from use, and obesity. The issues considered to cause greatest suffering for individual horses were delayed euthanasia, lack of recognition by owners of pain behaviour, large worm burdens, obesity and being fed unsuitable diets for equine feeding behaviour. These outcomes can help to focus research and education interventions on the most pressing welfare issues for horses.
\end{abstract}

Keywords: horse; welfare; Delphi method; health; behaviour; management; training; nutrition

\section{Introduction}

Survey studies and estimates suggest that there are around 7 million horses in the EU [1], with approximately one million horses in the UK (850,000 horses in England and Wales [2], 100,000 in Scotland [3] and approximately 160,000 in Ireland [4]. Although the majority of horses are kept as 
leisure animals, horses are unusual in that they are often not classified as companion animals (for example, only 58\% of horse owners classified horses as companion animals in a survey in Illinois [5]) and many do not live at the same address as their owners, but neither are they considered as livestock. In addition, although few horses in Europe are now used for draught purposes, a number of horses are also kept for racing, competitions and other professional uses [4] and are used in tourism, forestry, agriculture and therapy [1]. Globally, horses and other equids are still widely used for traction power in low- and middle-income countries [6], are used for meat in many countries and for conservation grazing, and there are also feral horse populations. Thus, there are multiple roles that are occupied by equids, which can carry different risks for horse welfare. In the UK, regardless of whether for professional or amateur use, most horses are ridden and trained by their owners, which can also result in particular welfare issues not experienced by other animals (e.g., bit lesions, aggressive riding style $[7,8])$.

Until relatively recently, horse welfare studies had focused primarily on stereotypic behaviour, horse transport and health-related issues. However, there has been a recent increase in the number of papers addressing varied horse welfare issues, considering the management of horses (such as pasture access [9], feeding strategies [10], rugging [11] and unwanted horses [5]), horse behaviour [12], horse welfare assessment [13] and particularly issues with the ridden horse and training methods [14,15]. These studies suggest that there are a significant number of horse welfare issues that may be overlooked by their owners, or are related to cultural or traditional methods of horse ownership and training.

Where there are many potential welfare issues (as have been suggested in previous studies [1,16-19]), it can sometimes be necessary to identify and prioritize the more important welfare issues for further research and/or education programs. A number of previous studies have used different types of qualitative techniques to determine what those who work with horses considered the most important welfare issues. Butler et al. [16] used focus groups of participants with experience of the racehorse industry to determine welfare priorities for racehorses and concluded that health issues were considered the most important. DuBois et al. [17] used a Delphi technique to identify the perceived prevalence of welfare issues for horses in Canada, suggesting that horses being denied access to important psychological or physical resources were the most important issues. Using qualitative interviewing approaches of various groups involved with horses, Horseman et al. [18] highlighted 45 welfare issues that potentially affected horses in GB, which were focused on health, management and training issues. A Delphi technique, with vignettes, was also used by Collins et al. [19], which particularly identified disposal of horses and behaviour at unregulated gatherings as issues for horses in Ireland.

Use of expert opinions, using methods such as Delphi, focus groups or semi-structured interviews, can be an efficient way to determine welfare priorities, particularly when there is limited empirical scientific data on which to base decisions. However, one of the limitations of this approach can be the repeatability of these studies, and whether another group of experts would reach the same conclusions and priorities. In addition, prioritization may be made for a number of different reasons, such as the feasibility of achieving an improvement in welfare. The aim of this study was to use a Delphi method firstly to gain a comprehensive understanding of the range of welfare issues experienced by horses in the UK (using a Delphi conference), and then to determine a prioritization following from the premise that, where the animals' capacities to suffer can be assumed, the most pressing issues are determined by the severity and duration of suffering and the number of animals affected [20]. Finally, the prioritization of welfare issues derived from our study is compared to other studies to address whether expert opinion is a suitable method for determining welfare priorities for horses. The results reported here are part of a larger study to determine the priority welfare issues for a range of different managed species in the UK. 


\section{Materials and Methods}

All research generated from this study was approved by the University of Edinburgh's Human Ethics Review Committee (HERC). The study formed part of a larger study to identify and prioritise welfare issues for a range of different species. Detailed methods were as previously described [21] and are given in brief here.

\subsection{Recruitment of Experts}

The aim was to recruit between 12 and 20 horse welfare experts to the study and to recruit a broad range of stakeholders, including practising veterinarians, academics, trainers, charity sector employees and equine industry representatives. Experts were defined as having worked in their field for at least 3 years and being based in the UK. Experts were recruited using a snowball sampling technique and were sent a consent form to sign in accordance with HERC guidelines before commencing the study.

\subsection{Horse Welfare Issues}

A list of horse welfare issues was developed through the use of a Delphi Conference procedure using an online discussion board. An initial list of horse welfare issues (derived from a list generated by the British Veterinary Association) was provided and experts were then able to add to and comment on issues anonymously for two weeks. All comments and discussion from the online platform were collated, and a detailed thematic analysis was conducted using NVivo 11 Pro. Using an emergent coding process, each comment from the board was categorized into themes, reaching saturation at 12 themes, which were later combined into 9 categories. Duplicate welfare issues were deleted, and the final list was checked by two independent assessors to remove redundancies or to add omissions.

\subsection{Questionnaires}

Two rounds of anonymous surveys were conducted using the Online Survey tool (formerly Bristol Online Survey, JISC, Bristol, UK). In both rounds, demographic data were collected from the experts including age, gender, expertise (experts could indicate expertise in more than one category; for example, they may be both veterinarians and academic researchers) and highest level of educational attainment.

For the first survey, participants were asked to score each of the potential welfare issues derived from the thematic analysis for severity (the intensity of suffering likely to be a consequence of the welfare issue in their opinion), duration (the estimated time period over which an animal was likely to experience the welfare issue in their opinion) and perceived prevalence (the likely proportion of the UK horse population they considered to be affected by the welfare issue). Each issue was scored on a 6 -point Likert scale for each factor, where $1=$ never/none, and $6=$ always/high. An even-numbered scale was chosen as this forced the experts to make a choice (prioritised or not).

The results of the first survey were reviewed and mean scores for each welfare issue and each factor calculated. Those issues that scored at least 3.0 or above (i.e., were considered by the experts to be at least somewhat important for any of the three welfare factors) were included in the second survey as a ranked list. In the second round, experts were asked whether they agreed or not with the ranking position, and whether, in their opinion, the issue should be ranked higher or lower. Agreement between experts was assessed by calculating Fleiss' kappa statistics and by assessing the proportion of experts that agreed with each rank position.

\subsection{Workshop}

The final stage of the process was an expert workshop conducted in Edinburgh over 2 days. This involved two horse welfare experts drawn from the experts who completed the earlier rounds, as well as 19 other experts from the wider study who had broad animal welfare expertise in other species, including farm and companion animals (overall workshop participants consisted of academics $=6$, veterinarians $=5$, industry representatives $=4$, charity/NGOs $=6$ ). Over the two days, experts 
participated in small-group (species-specific) and larger-group exercises to achieve a final rank order, working from the ranked prioritized lists of horse welfare issues that had been generated in the earlier rounds. In a few places, experts also combined areas which they felt to be too similar to separate. Consensus at the workshop was considered to be unanimous where a final list was produced with the agreement of all participants.

\section{Results}

\subsection{Expert Demographics}

Nineteen experts were recruited to the horse study. Experts had a mean age of 45 (SD = 7.89) and were predominantly female (17 female, 2 male). Experts were associated with NGOs or equine charities $(28 \%)$ or were academic researchers $(26 \%)$, trainers $(18 \%)$, industry representatives $(13 \%)$, veterinarians $(8 \%)$, associated with equine policy $(5 \%)$ or had other expertise $(2 \%)$. Experts were nearly all educated to at least university graduate level (94\%), with 53\% holding postgraduate qualifications (18\% Masters, 35\% PhD). The response rate was 68\% (first round) and 74\% (second round).

\subsection{Horse Welfare Issues}

Horse welfare experts generated a comprehensive list of 84 welfare concerns from the analysis of the discussion board. These were finally classified into 9 themes in preparation for the first online survey (Table 1).

Table 1. Welfare issues for horses (unranked) derived from thematic analysis of the anonymous online discussion boards, sorted for themes.

\begin{tabular}{cl}
\hline Category of Concern & Specific Welfare Issue \\
\hline & Lack of routine health care (e.g., vaccinations, dental, parasite prevention) \\
& Large worm burdens \\
& Lack of understanding re: worming/blanket worming, leading to resistance \\
& Lack of easy access to medications \\
& Lack of easy access to health care \\
& Delay in veterinary/professional engagement \\
& Lack of biosecurity and disease surveillance \\
& Lack of health checks at some ports/entry points, potential introduction of diseases \\
\hline & Neglect or sub-optimal care \\
& Lack of equine knowledge by owner ('laziness' to learn or refusal to change behaviour) \\
& Cultural influences e.g., 'letting nature take its course' \\
& Financial restrictions of owner for better livery arrangements/professional assistance \\
& Delayed euthanasia e.g., quality-of-life evaluation methods often not implemented \\
& Lack of a credible quality of life assessment mechanism \\
& Inappropriate re-homing, especially elderly; euthanasia would be more appropriate \\
& Lack of confidence in abattoir as an option for end of life \\
& Fundamental lack of owner understanding horse's ethological needs \\
& Anthropomorphism \\
& Rugging outside horses 24 h/d for half the year-no control if too hot/cold/itchy \\
'Well-meaning but ill-informed owners' (management traditions) \\
Inaccurate portrayal of stallions in our culture (feisty, difficult to handle) \\
Lack of recognition of pain behaviour before it becomes overt (e.g., can be \\
misinterpreted as 'bolshy'/naughty) \\
Culture of using horses in a utilitarian way \\
Growing population of owners not knowing where to obtain information \\
Owners receiving poor 'trusted information' from yard and online \\
Horses used as a status symbol e.g., upper levels of sport may depend on poor welfare \\
approaches \\
Use of horses as status symbols within the traveller community \\
Owner knowledge or \\
behaviour
\end{tabular}


Table 1. Cont.

\begin{tabular}{|c|c|}
\hline Category of Concern & Specific Welfare Issue \\
\hline $\begin{array}{c}\text { Nutrition and } \\
\text { management practices }\end{array}$ & $\begin{array}{l}\text { Obesity, e.g., due to lack of work, unrestricted grazing } \\
\text { Inappropriate diet, in particular, low-fibre, high energy concentrates, restricted access } \\
\text { to high-fibre forages } \\
\text { Rise in the blanket use of supplements } \\
\text { Undernourished (hunger) } \\
\text { Lack of access to fresh, clean water (thirst) } \\
\text { Feeding methods of stabled horsed contrary to their evolution (for low-energy forage) } \\
\text { Turned out } 24 / 7 \text { on green grass (e.g., relative high energy, risk of obesity/laminitis) } \\
\text { Poor field management, including ragwort, grazing too rich/poor, mud } \\
\text { Unsuitable living environment e.g., unsafe fencing }\end{array}$ \\
\hline $\begin{array}{c}\text { Work and training/horse } \\
\text { use }\end{array}$ & $\begin{array}{l}\text { Overworking young horses } \\
\text { Overweight riders or inappropriate for the horse/pony } \\
\text { Horses being competed which are unfit with unfit riders } \\
\text { Hirelings e.g., Scottish Common riding equines overused by novice/unbalanced riders } \\
\text { Injury during use, e.g., from racing, eventing, endurance events } \\
\text { Road racing horses (arguably not a traditional 'traveller/gypsy' activity) } \\
\text { Being ridden-not poor riding or training, but riding per se } \\
\text { Injury to hirelings (overweight riders, ill-fitting tack, overwork) } \\
\text { Unfit and unsuitable horses hired out } \\
\text { Inappropriate training methods e.g., punishment, negative reinforcement (bit or leg } \\
\text { pressure not removed), unclear signals, pain, flooding } \\
\text { Public unable to interpret/replicate some training methods e.g., natural horsemanship } \\
\text { Inappropriate and restrictive tack, e.g., poorly fitted saddle, certain bits/nosebands }\end{array}$ \\
\hline Horse behaviour & $\begin{array}{l}\text { Fear and stress arising from use (work, sport, entertainment), e.g., shows, racing, polo } \\
\text { Poor handling and training: confusion, conflict, frustration, distress, stress, fear and } \\
\text { sometimes pain as a result of the interactions they have with people } \\
\text { Lack of understanding of learning theory leading to poor training techniques } \\
\text { Poor weaning methods } \\
\text { Stabling 24/7-lack of natural behavioural expression due to restrictions } \\
\text { Social isolation (no or limited contact with own species) } \\
\text { Being kept in a herd that is constantly changing (unstable social groups) } \\
\text { Being kept where an individual animal cannot escape from aggressive animals } \\
\text { Being kept in group where dominant animals restrict access to resources } \\
\text { Restrictions on normal behaviours to satisfy basic dietary needs } \\
\text { Lack of environmental control/frustration-horse is motivated to act but cannot } \\
\text { Management of stallions-often isolated, unable to perform normal social interactions } \\
\text { Negative affective states e.g., atypical myopathy, fear, frustration, depression, anxiety } \\
\text { Boredom, even with access to turnout-usually a square monoculture field }\end{array}$ \\
\hline Service providers & $\begin{array}{l}\text { Unqualified service providers, e.g., unqualified farrier, dentistry, castration not by vet } \\
\text { Poor hoof care e.g., lack of care or trimming by owner (inappropriately) } \\
\text { Lack of regulation of trainers } \\
\text { Lack of animal establishment licensing } \\
\text { No regulation of small rescue establishments (sometimes hoarding) } \\
\text { Tendency (of industry) to tackle symptoms, not cause (e.g., livery layout, routines) } \\
\text { The passport process: not fit for purpose } \\
\text { Lack of licensing, inspection, or agreed standards of care in equine establishments (e.g., } \\
\text { livery yards, dealers, sanctuaries and rescues) }\end{array}$ \\
\hline
\end{tabular}


Table 1. Cont.

\begin{tabular}{cl}
\hline Category of Concern & Specific Welfare Issue \\
\hline \multirow{3}{*}{ Transport of horses } & Long-distance transport \\
& Some domestic/local journeys are made in inappropriate vehicles (unsafe) \\
& Little regard for fitness (of horse) to travel \\
\hline \multirow{5}{*}{ Stray or unwanted horses } & Stray and abandoned horses (injuries to themselves and others) \\
& Lack of enforced, mandatory Microchips-leads to abandonments \\
& Fly grazing \\
& Tethering without provision of adequate shelter, attention, water, etc \\
\hline \multirow{3}{*}{$\begin{array}{c}\text { Breeding and horse } \\
\text { trading }\end{array}$} & Breeding decisions e.g., exaggerated conformation \\
& Breeding low-value horses with conformational/physiological compromising \\
& conditions \\
& Broodmares being bred indiscriminately-i.e., 'given a job to do' when retired \\
& Indiscriminate breeding and failing to castrate colts \\
& Selling horses online-ill-prepared potential owners buying unsuitable horses \\
\hline
\end{tabular}

\subsection{Expert Rankings}

The outcome of the first ranking process conducted by experts is shown in Table 2. Of the initial 84 welfare issues shown in Table 1, 34, 37 and 35 issues were retained into round 2 for perceived prevalence, severity and duration of the welfare issue respectively.

Horse experts had an overall low level of agreement with the rank order generated in the first round survey (Fleiss' kappa $=0.259,0.227$ and 0.243 for perceived prevalence, severity and duration respectively), and generally less than $75 \%$ of experts agreed on the top 10 highest-ranking welfare issue for perceived prevalence, severity or duration, although there was better agreement $(70 \%-85 \%)$ on the five lowest ranking positions for all welfare issues. Experts considered that lack of understanding of horse welfare needs by owners, over-rugging, inappropriate training and handling, and delayed euthanasia were more prevalent than as scored in the first round. In addition, hunger and obesity were considered less severe, but lack of recognition of pain behaviour, delayed euthanasia and inability to perform normal social behaviours were more severe (see Supplementary Material for details). 
Table 2. Mean scores (with SD) and rank order for horse welfare issues that scored at least mean 3.0 or above for perceived prevalence, severity and duration of the welfare issue (issues scored using a Likert scale from 1-6, where $1=$ never/none, and $6=$ always/high).

\begin{tabular}{|c|c|c|c|c|c|c|}
\hline $\begin{array}{l}\text { Rank } \\
\text { Order }\end{array}$ & Perceived Prevalence & $\begin{array}{l}\text { Mean Score } \\
\quad \text { (SD) }\end{array}$ & Severity & $\begin{array}{l}\text { Mean Score } \\
\quad \text { (SD) }\end{array}$ & Duration & $\begin{array}{l}\text { Mean Score } \\
\text { (SD) }\end{array}$ \\
\hline 1 & $\begin{array}{l}\text { Lack of recognition of pain behaviour (e.g., can be } \\
\text { misinterpreted as naughty) }\end{array}$ & $4.88(1.08)$ & Hunger & $5.25(0.87)$ & $\begin{array}{l}\text { Obesity (e.g., due to lack of work, unrestricted } \\
\text { grazing) }\end{array}$ & $5.00(1.00)$ \\
\hline 2 & Use of inappropriate training and handling & $4.82(1.08)$ & Lack of access to clean/fresh water & $5.08(1.62)$ & $\begin{array}{l}\text { Lack of recognition of pain behaviour (e.g., } \\
\text { can be misinterpreted as naughty) }\end{array}$ & $4.96(1.04)$ \\
\hline 3 & $\begin{array}{l}\text { Obesity (e.g., due to lack of work, unrestricted } \\
\text { grazing) }\end{array}$ & $4.75(0.75)$ & $\begin{array}{l}\text { Obesity (e.g., due to lack of work, unrestricted } \\
\text { grazing) }\end{array}$ & $4.92(1.38)$ & Hunger & $4.60(1.35)$ \\
\hline 4 & Delayed euthanasia decisions & $4.58(0.90)$ & $\begin{array}{l}\text { Lack of recognition of pain behaviour (e.g., } \\
\text { can be misinterpreted as naughty) }\end{array}$ & $4.79(1.13)$ & $\begin{array}{l}\text { Inability to perform normal social interactions } \\
\text { (including social isolation, stabling 24/7) }\end{array}$ & $4.55(1.29)$ \\
\hline 5 & Poor pasture management & $4.50(1.00)$ & $\begin{array}{l}\text { Racing horses on the road (usually by gypsy/ } \\
\text { travellers) }\end{array}$ & $4.55(1.44)$ & Lack of biosecurity and disease surveillance & $4.30(1.51)$ \\
\hline 6 & $\begin{array}{l}\text { Lack of understanding of horse welfare needs by } \\
\text { owner/carer }\end{array}$ & $4.5(1.24)$ & Delayed euthanasia decisions & $4.46(1.04)$ & Delayed euthanasia decisions & $4.28(1.43)$ \\
\hline 7 & Over-rugging (horse lacks control if too hot/cold) & $4.42(0.99)$ & Lack of biosecurity and disease surveillance & $4.46(1.13)$ & $\begin{array}{l}\text { Lack of routine health care (e.g., vaccinations, } \\
\text { dental, parasite prevention) }\end{array}$ & $4.25(1.14)$ \\
\hline 8 & Lack of biosecurity and disease surveillance & $4.42(1.24)$ & Long-distance transport & $4.42(1.38)$ & Large worm burdens & $4.23(0.93)$ \\
\hline 9 & Poor handling methods & $4.33(1.30)$ & $\begin{array}{l}\text { Inability to perform normal social interactions } \\
\text { (including social isolation, stabling 24/7) }\end{array}$ & $4.37(1.08)$ & Poor owner knowledge of horse care & $4.21(1.21)$ \\
\hline 10 & Poorly fitting and restrictive tack & $4.25(1.06)$ & Overworking & $4.36(1.36)$ & Poor pasture management & $4.18(1.36)$ \\
\hline 11 & $\begin{array}{l}\text { Poor quality information available (online or from } \\
\text { others) }\end{array}$ & $4.25(1.36)$ & Poorly fitting and restrictive tack & $4.33(1.44)$ & $\begin{array}{l}\text { Over-rugging (horse lacks control if too } \\
\text { hot/cold) }\end{array}$ & $4.18(1.47)$ \\
\hline 12 & Unstable social groups (herd constantly changing) & $4.08(1.38)$ & Abandonment or stray horses & $4.27(1.19)$ & $\begin{array}{l}\text { Unsuitable diets for equine feeding behaviour } \\
\text { (e.g., feeding methods of stabled horses, } \\
\text { turned out } 24 / 7 \text { ) }\end{array}$ & $4.18(1.29)$ \\
\hline 13 & $\begin{array}{l}\text { Inability to perform normal social interactions } \\
\text { (e.g., social isolation, stabling 24/7) }\end{array}$ & $4.00(1.23)$ & $\begin{array}{l}\text { Unsuitable diets for equine feeding behaviour } \\
\text { (e.g., feeding methods of stabled horses, } \\
\text { turned out 24/7) }\end{array}$ & $4.26(1.23)$ & Inappropriate use of food supplements & $4.10(1.10)$ \\
\hline 14 & $\begin{array}{l}\text { No regulation of establishments or service } \\
\text { providers }\end{array}$ & $3.97(1.47)$ & Overweight riders for horse & $4.25(1.14)$ & Poor hoof care & $4.10(1.10)$ \\
\hline 15 & $\begin{array}{l}\text { Unsuitable diets for equine feeding behaviour } \\
\text { (e.g., feeding methods of stabled horses, turned } \\
\text { out } 24 / 7 \text { ) }\end{array}$ & $3.93(1.51)$ & Use of inappropriate training and handling & $4.22(1.44)$ & Neglect of sub-optimal care & $4.09(1.04)$ \\
\hline 16 & $\begin{array}{l}\text { Negative affective states (fear, frustration, } \\
\text { boredom, depression, anxiety) }\end{array}$ & $3.92(1.38)$ & $\begin{array}{l}\text { Unavoidable aggressive social interactions } \\
\text { (e.g., restricted resources in groups) }\end{array}$ & $4.13(1.44)$ & $\begin{array}{l}\text { No regulation of establishments or service } \\
\text { providers }\end{array}$ & $4.09(1.48)$ \\
\hline
\end{tabular}


Table 2. Cont.

\begin{tabular}{|c|c|c|c|c|c|c|}
\hline $\begin{array}{l}\text { Rank } \\
\text { Order }\end{array}$ & Perceived Prevalence & $\begin{array}{l}\text { Mean Score } \\
\text { (SD) }\end{array}$ & Severity & $\begin{array}{l}\text { Mean Score } \\
\quad \text { (SD) }\end{array}$ & Duration & $\begin{array}{l}\text { Mean Score } \\
\quad \text { (SD) }\end{array}$ \\
\hline 17 & Poor pasture management & $3.90(1.00)$ & Neglect or sub-optimal care & $4.08(1.31)$ & $\begin{array}{l}\text { Negative affective states (fear, frustration, } \\
\text { boredom, depression, anxiety) }\end{array}$ & $4.09(0.99)$ \\
\hline 18 & Neglect or sub-optimal care & $3.78(1.01)$ & $\begin{array}{l}\text { Tethering without provision of shade, water } \\
\text { etc. }\end{array}$ & $4.08(1.68)$ & $\begin{array}{l}\text { Lack of understanding of horse welfare needs } \\
\text { by owner/carer }\end{array}$ & $4.07(1.79)$ \\
\hline 19 & Horse passports not fit for purpose & $3.77(1.35)$ & Large worm burdens & $4.00(1.29)$ & Overweight riders for horse & $4.00(1.18)$ \\
\hline 20 & Overworking & $3.73(1.29)$ & Poor hoof care & $4.00(1.10)$ & Poorly fitting and restrictive tack & $4.00(1.34)$ \\
\hline 21 & Poor health knowledge by owner & $3.69(0.80)$ & Hiring horses to unsuitable riders & $3.95(1.21)$ & Use of inappropriate training and handling & $3.93(1.35)$ \\
\hline 22 & Poor weaning methods & $3.64(1.50)$ & Poor weaning methods & $3.92(1.56)$ & Poor weaning methods & $3.91(1.92)$ \\
\hline 23 & Delay in seeking veterinary care & $3.62(1.33)$ & Poor health knowledge by owner & $3.92(1.64)$ & $\begin{array}{l}\text { Indiscriminate breeding (including of } \\
\text { compromised animals) }\end{array}$ & $3.91(1.48)$ \\
\hline 24 & Overweight riders for horse & $3.58(1.31)$ & $\begin{array}{l}\text { No regulation of establishments or service } \\
\text { providers }\end{array}$ & $3.91(1.31)$ & $\begin{array}{l}\text { Unstable social groups (herd constantly } \\
\text { changing) }\end{array}$ & $3.82(1.33)$ \\
\hline 25 & Inappropriate use of food supplements & $3.58(1.31)$ & $\begin{array}{l}\text { Over-rugging (horse lacks control if too } \\
\text { hot/cold) }\end{array}$ & $3.83(1.34)$ & Tethering without access to shade, water etc. & $3.73(1.62)$ \\
\hline 26 & $\begin{array}{l}\text { Indiscriminate breeding (including of } \\
\text { compromised animals) }\end{array}$ & $3.46(1.31)$ & Poor owner knowledge of horse care & $3.82(1.24)$ & Abandonment or stray horses & $3.70(1.42)$ \\
\hline 27 & Poor hoof care & $3.45(0.93)$ & Horse passports not fit for purpose & $3.82(1.40)$ & Poor health knowledge by owner & $3.70(1.79)$ \\
\hline 28 & Being ridden & $3.42(1.93)$ & $\begin{array}{l}\text { Negative affective states (fear, frustration, } \\
\text { boredom, depression, anxiety) }\end{array}$ & $3.77(1.62)$ & Lack of access to clean/fresh water & $3.64(1.69)$ \\
\hline 29 & $\begin{array}{l}\text { Fear, stress or injury from use in work, sport or } \\
\text { entertainment }\end{array}$ & $3.35(1.53)$ & Delay in seeking veterinary care & $3.75(1.60)$ & Hiring horses to unsuitable riders & $3.54(1.03)$ \\
\hline 30 & $\begin{array}{l}\text { Lack of routine health care (e.g., vaccinations, } \\
\text { dental, parasite prevention) }\end{array}$ & $3.23(0.93)$ & $\begin{array}{l}\text { Unstable social groups (herd constantly } \\
\text { changing) }\end{array}$ & $3.67(1.50)$ & $\begin{array}{l}\text { Unavoidable aggressive social interactions } \\
\text { (e.g., restricted resources in groups) }\end{array}$ & $3.46(1.51)$ \\
\hline 31 & Hiring horses to unsuitable riders & $3.17(1.47)$ & Poor pasture management & $3.65(1.17)$ & Long-distance transport & $3.45(1.37)$ \\
\hline 32 & Poor transport of horses on domestic journeys & $3.14(1.12)$ & $\begin{array}{l}\text { Lack of understanding of horse welfare needs } \\
\text { by owner/carer }\end{array}$ & $3.64(1.37)$ & $\begin{array}{l}\text { Fear, stress or injury from use in work, sport } \\
\text { or entertainment }\end{array}$ & $3.44(1.18)$ \\
\hline 33 & Long-distance transport & $3.00(1.41)$ & $\begin{array}{l}\text { Fear, stress or injury from use in work sport or } \\
\text { entertainment }\end{array}$ & $3.63(1.00)$ & $\begin{array}{l}\text { Flygrazing (grazing horses without } \\
\text { landowners permission) }\end{array}$ & $3.40(1.78)$ \\
\hline 34 & $\begin{array}{l}\text { Unavoidable aggressive social interactions (e.g., } \\
\text { restricted resources in groups) }\end{array}$ & $3.00(1.04)$ & $\begin{array}{l}\text { Indiscriminate breeding (including of } \\
\text { compromised animals) }\end{array}$ & $3.62(1.06)$ & Overworking & $3.34(1.19)$ \\
\hline 35 & & & $\begin{array}{l}\text { Lack of routine health care (e.g., vaccinations, } \\
\text { dental, parasite prevention) }\end{array}$ & $3.42(0.90)$ & Lack of easy access to health care & $3.09(0.98)$ \\
\hline 36 & & & Poor transport of horses on domestic journeys & $3.31(1.37)$ & & \\
\hline 37 & & & Lack of easy access to health care & $3.25(1.31)$ & & \\
\hline
\end{tabular}




\subsection{Workshop Rankings}

The workshop was more successful than the anonymous online surveys in achieving a consensus (unanimity was achieved), and over two days of discussion, a final welfare ranking on which the experts agreed was achieved (Table 3).

Table 3. Ranked prioritized welfare issues for horses derived from the workshop for individual horses (combined severity and duration of the welfare issue in the experts' opinion) and for the UK horse population (perceived prevalence).

\begin{tabular}{|c|c|c|}
\hline Rank Order & $\begin{array}{c}\text { Horse Population } \\
\text { (Perceived Prevalence) }\end{array}$ & $\begin{array}{c}\text { Individual Horses } \\
\text { (Severity + Duration) }\end{array}$ \\
\hline 1 & $\begin{array}{c}\text { Lack of biosecurity and disease } \\
\text { surveillance }\end{array}$ & Delayed euthanasia decisions \\
\hline 2 & Delayed euthanasia decisions & $\begin{array}{l}\text { Lack of recognition of pain } \\
\text { behaviour }\end{array}$ \\
\hline 3 & $\begin{array}{l}\text { Lack of understanding of horse } \\
\text { welfare needs by owner/carer }\end{array}$ & Large worm burdens \\
\hline 4 & $\begin{array}{l}\text { Fear/stress/frustration from use in } \\
\text { work, sport or entertainment }\end{array}$ & Obesity \\
\hline 5 & Obesity & $\begin{array}{l}\text { Unsuitable diets for equine } \\
\text { feeding behaviour }\end{array}$ \\
\hline 6 & $\begin{array}{l}\text { Indiscriminate/inappropriate } \\
\text { breeding }\end{array}$ & Hunger \\
\hline 7 & Poorly fitting and restrictive tack & $\begin{array}{l}\text { Inability to perform normal social } \\
\text { interactions }\end{array}$ \\
\hline 8 & Unstable social groups & Negative affective states \\
\hline 9 & $\begin{array}{l}\text { Unsuitable diets for equine } \\
\text { feeding behaviour }\end{array}$ & Overworking \\
\hline 10 & Poor weaning methods & Overweight riders \\
\hline
\end{tabular}

\section{Discussion}

Although the horse experts in the initial rounds of the Delphi did not achieve very high levels of agreement, a better consensus was achieved during the face-to-face discussions in the workshop, and many of the areas considered to be important in the survey were also ranked highly in the workshop. Overall concerns reflected all aspects of horse management and use, from health (biosecurity, worm burdens and delayed euthanasia decisions), owner knowledge (lack of recognition of pain behavior and lack of understanding of equine welfare needs), management (diets, weaning and social groups) and use of horses (fear and frustration, overwork, poorly fitting tack and inappropriate rider weight). The initial rounds of the Delphi were anonymous and had the advantage that individual respondents were not influenced by the decisions of others. However, a disadvantage of the Delhpi method is that it prevents live discussion where individual ideas and perceptions can be broken down, discussed and reassessed. In our study, we found that considered discussion, in a structured way in the workshop, allowed a better consensus to be achieved, building on the preliminary analyses derived in the anonymous process.

Other qualitative studies that have considered horse welfare have used varying techniques, and not all studies yielded outcomes that could be directly compared to our prioritization. However, a UK study using interviewing and focus groups of industry professionals [18] found that horses being underweight or overweight, poor foot care, internal worms and laminitis were the most frequently mentioned horse health issues. Large worm burdens, obesity and hunger all also appeared in the most important issues in our study for individual horses. Likewise, prolonged stabling, under- or 
over-feeding, inappropriate rugging and social isolation were identified in previous work [18] and were also considered important in our study for individual horses, and feeding of unsuitable diets was perceived to be prevalent. Use of poorly fitting tack was identified in both studies as a significant cause for welfare concern. In the study of Horseman et al. [18], the most prevalent welfare issues (identified as the perception by stakeholders to be the situations in which welfare was most likely to be compromised) were keeping horses in unsuitable environments, inappropriate use, misunderstanding behaviour, disruption of social routines (e.g., through moving yards), abandonment, transport and delayed euthanasia. Of these, issues with delayed euthanasia, lack of owner understanding, issues with use and instability of social routines were also considered by the experts in our study to be prevalent with horses in the UK. A Delphi study conducted in Canada identified lack of owner knowledge, delayed euthanasia decisions, inappropriate training or use, inappropriate feeding, lack of turnout and lack of social companions as important welfare issues at the individual horse level and issues with breeding, delayed euthanasia, biosecurity and owner ignorance as important welfare issues at the population level [17]. Finally, a study using the Five Domains Framework to assess horse welfare issues within different categories [22] concluded that the most severe impacts on horse welfare were abrupt individual weaning, feeding 100\% low-energy concentrate, use of indoor tie-stalls without social contact, forced flexion (sometimes called 'Rollkur' or hyperflexion [15]), restrictive nosebands, ear twitches and transport, either individually or in a group with unfamiliar companions. A number of veterinary procedures or surgical interventions were also identified as causing severe welfare impacts [22]. However, this study did not assess the likelihood or prevalence of these issues, only the most severe within a set of specific categories.

Despite use of different qualitative methods, different selection of experts or industry professionals, and different ways of prioritization, there are a number of similar issues that have arisen in UK and Canada that may reflect general areas of concern for the welfare of horses. In our study, we specifically asked experts to address welfare by focusing on the amount of suffering caused by the welfare issue. The study of McGreevy et al. [22] used the Five Domains model, which asked experts to focus on the impact on the mental state of the horses in determining the welfare impact. Although other studies did not appear to use a specific definition of welfare to direct respondents, participants may have utilized similar thinking about the impact on equine mental state and suffering of the welfare issues that were mentioned frequently. Other studies have also identified racehorses or competition horses $[17,18]$ and horses owned by travellers [18] as areas of particular welfare concern. In our study, although these areas were mentioned in the initial rounds of developing the lists of horse welfare concerns, they were not included in the final prioritization. Recent studies of racehorse welfare [16] and perceptions of welfare in travellers [23] have addressed these issues and suggest that some concerns may be misplaced, which perhaps reflects the lower concern for these areas in our study.

\subsection{Owner Knowledge and Understanding}

Of the issues that arose in all studies, owners' lack of knowledge, particularly in relation to horse behaviour, was clearly highlighted. In our study, this was identified as a specific theme in the initial development of the list of welfare concerns for horses and was also included as one of the most important issues in the final rankings for recognition of pain behaviour and lack of knowledge of horse welfare needs. Lack of owner knowledge may also contribute to other welfare issues, such as inappropriate feeding and training methods and use of restrictive or poorly-fitting tack. In their review of recreational horse management, Hemsworth et al. [24] suggest that a number of horse owner attributes might contribute to poor horse welfare, including commitment to horse ownership, income, education, knowledge of horse husbandry and attitude to horse management. Of these, levels of education and income, as well as lack of knowledge, have been shown to be associated with horses having welfare problems [24]. Hartmann et al. [25] found high agreement amongst Scandinavian horse owners that horses should be kept in groups but also observed that many horses were not kept with 
social companions, suggesting that factors other than just lack of knowledge, such as opportunity or financial ability to manage horses differently, may also contribute.

A number of studies have suggested that the vast majority of owners believe horses to be sentient and capable of specific emotions such as pain, fear or joy [26,27]. However, DuBois et al. [27] suggest that belief in sentience did not appear to reflect understanding of welfare issues. In a recent survey [28], horse owners could recognize at least some behaviours associated with distress but missed or incorrectly classified behavioural indicators of negative affective states as positive. Further, a number of participants in the survey indicated that they would be happy for their horse to be treated by methods they had already identified as causing distress [28], suggesting that knowledge was not the only factor involved in poor horse welfare.

The impact of owner knowledge or management responses has also been shown to be an issue with health practices as well as behaviour. Although lack of knowledge or understanding was not specifically assessed, Thompson et al. [29] found that 19\% of Australian horse owners did not vaccinate their horses against tetanus, and 11\% did not ensure regular dental care. In addition, McGowan et al. [30] demonstrated that owners could not identify all clinical signs of ill health in their aged equines and did not seek veterinary advice in all cases when it was warranted. These data support the view that lack of sufficient owner knowledge can contribute to poor health and welfare in horses. However, other barriers to improving horse welfare may be related to financial constraints, opportunity to change practices, habit and cultural norms around horse management.

\subsection{Delayed Euthanasia Decisions}

The consequences of delaying euthanasia decisions, and so increasing the risk of animals suffering uncontrollable pain or disease, was considered by experts in this study to be one of the most prevalent horse welfare issues and to cause the greatest suffering to individual horses. Delayed euthanasia was also identified as important in two other studies that have attempted to prioritize horse welfare issues $[17,18]$, suggesting that this is widely considered an important issue for horses. This may be attributable to owners' lack of knowledge or ability to correctly identify and understand the consequences of clinical symptoms as discussed above, and may also be related to issues with income or ability to pay for horses to be euthanized. Horse slaughter at abattoirs is permitted in the UK, which may alleviate some of the financial impact of euthanasia, and has been suggested to improve horse welfare [31]. However, other issues such as emotional attachment, peer pressure and negative attitudes to death can also play a role [18]. Currently, there is little published research to allow quantification of the impact of delayed euthanasia on horse welfare, although many veterinary clinics and charities do provide guidance on recognizing a deteriorating quality of life (e.g., www.bluecross.org.uk and www.bhs.org.uk) or emergency conditions where euthanasia would be recommended.

\subsection{Impact of Inappropriate Training or Use of Horses}

Horses are unusual amongst other domesticated species in the degree of use and training that they usually receive, often by owners who themselves have had no specific education in learning theory or training practices. This lack of owner knowledge of equine learning or training methods was a significant concern in our study and in others [17,18,22]. There has been a recent increase in scientific studies assessing the impact of training, tack use and competition on equine welfare. For example, studies have shown significant lesions in the mouths of Finnish trotters and Icelandic horses when used in competition from the action of the bit [7,32]. The use of coercive hyperflexion of the head and neck or Rollkur, for example in dressage horses, has been shown to cause adverse behavioural [15] and physiological indicators [33], suggesting increased stress in these animals compared to working in a less flexed position. Application of the Five Domains model also identified working in Rollkur as one of the most adverse welfare impacts in foundation training [22]. As already described, a recent study [28] has shown that conflict, stress, fear and frustration were identified as present in a variety of different training and riding disciplines, including natural horsemanship and bridleless riding, and that not all 
horse owners perceived this to be inappropriate for horse handling. In our study, the misclassification of pain-related behavioural responses as 'naughty' was considered to be a significant source of equine suffering and suggests that owner knowledge about equine behaviour, attitudes and understanding of animal pain and beliefs about particular rising practices may need to be tackled to improve equine welfare.

\subsection{Inappropriate Feeding}

Concerns about feeding practices in our study were either about the quantity of feed given (i.e., that horses were fed too much and were overweight, or not enough and thus were thin or hungry) or that the method of feeding management, such as restricted forage access, might cause adverse behavioural consequences for horses.

Studies in the UK, Sweden, Italy, Germany and the USA suggest that between $25 \%$ and $45 \%$ of horses and ponies are overweight or obese [13,34-37]. These studies confirm that this is indeed a prevalent condition as identified by experts in our study. Obesity is associated with insulin resistance, equine metabolic syndrome [38] and increased likelihood of laminitis (a painful condition of the feet that can result in euthanasia), as well as issues with heat stress, reproductive and inflammatory responses [39]. Thus, obesity is a significant risk factor for poor welfare from the painful and debilitating conditions that are predisposed. By contrast, for horses that were not fed enough food in our study, it was the negative feelings associated with lack of food, i.e., hunger, that were identified as the welfare issue, rather than specifically the consequences of being underweight. In survey studies, only $2 \%$ of horses were considered in poor body condition in Scotland [34] and $4.5 \%$ in older horses ( $>15$ years) in England and Wales [40]. Thus, it seems that hunger from chronic lack of food does not occur at high prevalence in the UK, although the severity of the condition was the predominant issue for experts in this study. Hunger can occur because horses might be left without food for prolonged periods, even if the intention is to reduce weight in obese animals, such as managing overweight horses on a drylot [36]. Bedding investigation and bedding eating have been suggested to be indicators of feeding frustration which may be associated with hunger [41], and increased motivation to access feed is usually considered an indicator of hunger in other species [42]. Periods of food deprivation have also been linked to an increase in gastric ulceration [43] and are a risk factor for the development of stereotypic behaviour [44].

Actions to manage the weight of horses can induce hunger and/or frustration in horses, as described above. However, these emotional states may also occur when horses are fed in ways that are very different from their evolved feeding responses. In our study, feeding animals unsuitable diets for equine feeding behaviour was considered by experts to be both an important cause of horses suffering and to be prevalent. Feral horses spend 12-18 hours a day grazing [45], and their digestive system is adapted to a continuous intake of relatively poor quality forage. Feeding management of stabled horses may often utilize feed restriction (as described above), and feeding in 'meals' rather than continuous forage. A survey of UK horse owners found that $4 \%$ were continuously housed, and $92 \%$ had pasture access for an average of between 70 and 126 hours per week [46], suggesting that horses were spending between $25 \%$ and $58 \%$ of their time stabled. The majority ( $82 \%$ ) of horses received additional forage feeds (such as hay) and concentrate feeds $(86 \%)$, although the frequency of feeds was not reported [46]. The study of McGreevy et al. [22] concluded that feeding a 100\% concentrate diet, even if this met the horses' metabolic needs, had the most adverse impact on welfare through its impact on behaviour and that pasture choice and feeding forage were the least likely to impact welfare. Rochais et al. [10] showed that feeding systems that encouraged a longer period of feeding were also associated with reduced stereotypic responses and more positive behavioural change in horses.

\subsection{Inappropriate Environments and Social Behaviour}

In our study, issues with social behaviours were considered both to be prevalent (instability of social groups) and to cause significant suffering to individual horses (inability to perform normal 
social interactions). Prolonged stabling and management in inappropriate environments were identified as welfare issues in the study of Horseman et al. [18]. In our study, it was the impact of housing/management on social contact that was considered the greatest issue, although these issues are often experienced together. The study of McGreevy et al. [22] also concluded that worse welfare was experienced by animals kept either indoors or restricted outdoors (tethered) without social contact and that best welfare was achieved by living outdoors with full social contact. Horses are social animals, and keeping them in groups is widely considered to be important for good welfare [47]. For example, horses have been shown to have a high motivation to maintain full, or partial social contact with another horse [48], and stereotypic behaviour is linked to single housing [49].

Various studies suggest that $83 \%-92 \%$ of horses are continuously managed at pasture in groups or have pasture access $[25,46,50]$ but $4 \%-10 \%$ of horses may be continuously housed with little or no exercise opportunities $[13,25,46]$. This figure was higher for entire male horses, where nearly $40 \%$ were found to be kept alone in a Nordic study [25]. Of the stabled horses in a study of Italian and German horse welfare [13], 22\% of horses had no physical or visual contact with other horses. These data suggest that a significant percentage of horses are kept in environments that may prevent social contact for at least some of the day and that a small percentage of horses may have no access to other horses for prolonged periods of time. Nearly $20 \%$ of stabled horses have been shown to display stereotypic behaviours [13], suggesting that welfare is compromised in these animals.

\section{Conclusions}

By comparing the outcomes from our data with those of other studies that have attempted similar types of assessments, we have found that there are common welfare concerns that are raised frequently with different groups, which lends greater weight to arguments that these are important issues for horse welfare. In particular, lack of owner knowledge, or application of knowledge to the management of horses, is an important welfare concern, which has also been seen in other species [21,51]. In addition, many of the other issues that have been highlighted may also stem from poor owner knowledge or the application of traditional or culturally mediated methods of managing or using horses. These include poor biosecurity practices, not recognizing pain behaviour, use of poorly fitting or restrictive tack, inappropriate training practices and keeping horses in environments that do not meet their physical, nutritional or behavioural welfare needs. Increasing numbers of studies have demonstrated that these practices can result in fear, frustration or distress in horses, and an effective means to transfer this knowledge to owners and an assessment of the barriers to implementing changes are required.

One of the limitations of a Delphi procedure, and for other techniques that rely on expert opinion, is that the outcomes reflect only the knowledge and understanding of the experts [52]. However, it is a useful technique when empirical data are not available, or when comparisons of, for example, chronic versus acute conditions are attempted. Although it uses a consensus approach and seeking experts from a range of different backgrounds [53] can improve the issue, it is still a possibility that this does not reflect reality and a different group of experts might achieve a different outcome. However, by comparing our outcomes with other studies that have used similar approaches, we have been able to overcome this issue and hence conclude that a consensus on priority horse welfare issues has been achieved.

Supplementary Materials: The following are available online at http://www.mdpi.com/2076-2615/10/4/647/s1, Table S1: Percentage agreement with the ranking of horse issues from first online survey scored by experts in the second online survey.

Author Contributions: Conceptualization: C.M.D., M.C. and H.B.; methodology, F.C.R.-L. and C.M.D.; formal analysis, F.C.R.-L.; investigation, F.C.R.-L.; writing-original draft preparation, F.C.R.-L. and C.M.D.; writing-review and editing, M.C., H.B. and C.M.D.; supervision, C.M.D.; project administration, C.M.D.; funding acquisition, C.M.D., M.C. and H.B. All authors have read and agreed to the published version of the manuscript. 
Funding: This study was funded by the Animal Welfare Foundation (AWF). AWF is a fundraising and grant-giving charity (charity number 287118) directed by veterinary professions, which uses veterinary knowledge to improve the welfare of animals through science, education and debate. More information can be found at www. animalwelfarefoundation.org.uk

Acknowledgments: We thank all the experts who took part in the study for their time and dedication and the 144 experts who took part in the larger study.

Conflicts of Interest: The authors declare no conflict of interest. The funders had no role in the design of the study; in the collection, analyses, or interpretation of data; in the writing of the manuscript, or in the decision to publish the results.

\section{References}

1. Removing the Blinkers: The Health and Welfare of European Equidae in 2015. Available online: https://www. eurogroupforanimals.org/wp-content/uploads/EU-Equine-Report-Removing-the-Blinkers.pdf (accessed on 9 January 2020).

2. Boden, L.A.; Parkin, T.D.H.; Yates, J.; Mellor, D.; Kao, R.R. Summary of current knowledge of the size and spatial distribution of the horse population within Great Britain. BMC Vet. Res. 2012, 8, 43. [CrossRef] [PubMed]

3. Micoud, N.; McKnight, G.; Mauchlen, H. Scoping Study on the Equine Industry in Scotland. 2015. Available online: https://www.sruc.ac.uk/download/downloads/id/2391/2015_Scoping_study_on_the_ equine_industry_in_Scotland.pdf (accessed on 22 January 2020).

4. Collins, J.; Harlon, A.; More, S.J.; Duggan, V. The structure and regulation of the Irish equine industries: Links to considerations of equine welfare. Ir. Vet. J. 2008, 11, 746-756. [CrossRef] [PubMed]

5. Myers, K.; Mohammed, F.; Rickard, J.W.; Meyer, D.E.; Spaulding, A.D. Unwanted horse population in Illinois: Perceptions of horse owners, non-horse owners, and equine industry stakeholders. J. Appl. Anim. Welf. Sci. 2019, 22, 97-104. [CrossRef] [PubMed]

6. Minero, M.; Canali, E. Welfare issues of horses: An overview and practical recommendations. Ital. J. Anim. Sci. 2009, 8, 219-230. [CrossRef]

7. Tuomola, K.; Maki-Kihnia, N.; Kujala-Wirth, M.; Mykkanen, A.; Valros, A. Oral lesions in the bit area in Finnish Trotters after a race: Lesion evaluation, scoring, and occurrence. Front. Vet. Sci. 2019, 6, 206. [CrossRef]

8. Waite, K.; Heleski, C.; Ewing, M. Quantifying aggressive riding behavior of youth barrel racers and conflict behaviors of their horses. J. Vet. Behav. Clin. Appl. Res. 2018, 24, 36-41. [CrossRef]

9. Hockenhull, J.; Creighton, E. Management practices associated with owner-reported stable-related and handling behaviour problems in UK leisure horses. Appl. Anim. Behav. Sci. 2015, 155, 49-55. [CrossRef]

10. Rochais, C.; Henry, S.; Hausberger, M. "Hay-bags" and "Slow feeders": Testing their impact on horse behaviour and welfare. Appl. Anim. Behav. Sci. 2018, 198, 52-59. [CrossRef]

11. Hartmann, E.; Boe, K.E.; Jorgensen, G.H.M.; Mejdell, C.M.; Dahlborn, K. Management of horses with focus on blanketing and clipping practices reported by members of the Swedish and Norwegian equestrian community. J. Anim. Sci. 2017, 95, 1104-1117. [CrossRef]

12. Hothersall, B.; Casey, R. Undesired behaviour in horses: A review of their development, prevention, management and association with welfare. Equine Vet. Educ. 2012, 24, 479-485. [CrossRef]

13. Dalla Costa, E.; Dai, F.; Lebelt, D.; Scholz, P. Initial outcomes of a harmonized approach to collect welfare data in sport and leisure horses. Animal 2017, 11, 254-260. [CrossRef] [PubMed]

14. Fenner, K.; Caspar, G.; Hyde, M.; Henshall, C.; Dhand, N.; Probyn-Rapsey, F.; Dashper, K.; McLean, A.; McGreevy, P. It's all about the sex, or is it? Humans, horses and temperament. PLoS ONE 2019, 14, e0216699. [CrossRef] [PubMed]

15. Von Borstel, U.U.; Duncan, I.J.H.; Shoveller, A.K.; Merkies, K.; Keeling, L.J.; Millman, S.T. Impact of riding in a coercively obtained Rollkur posture on welfare and fear of performance horses. Appl. Anim. Behav. Sci. 2009, 116, 228-236. [CrossRef]

16. Butler, D.; Valenchon, M.; Annan, R.; Whay, H.R.; Mullan, S. Stakeholder perceptions of the challenges to racehorse welfare. Animals 2019, 9, 134. [CrossRef]

17. DuBois, C.; Odame, H.H.; Haley, D.B.; Merkies, K. An exploration of industry expert perception of Canadian equine welfare using a modified Delphi technique. PLOS ONE 2018, 13, e0201363. [CrossRef] 
18. Horseman, S.V.; Buller, H.; Mullan, S.; Whay, H.R. Current welfare problems facing horses in Great Britain as identified by equine stakeholders. PLoS ONE 2016, 11, e0160269. [CrossRef]

19. Collins, J.; Hanlon, A.; More, S.J.; Wal, P.G.; Duggan, V. Policy Delphi with vignette methodology as a tool to evaluate the perception of equine welfare. Vet. J. 2009, 181, 63-69. [CrossRef]

20. Kirkland, J.K.; Sainsbury, A.W.; Bennett, P.M. The welfare of free-living wild animals: Methods of assessment. Anim. Welf. 1994, 3, 257-273.

21. Rioja-Lang, F.; Bacon, H.J.; Connor, M.; Dwyer, C.M. Rabbit welfare: Determining priority welfare issues for pet rabbits using a modified Delphi method. Vet. Rec. Open 2019, 6, e000363. [CrossRef]

22. McGreevy, P.; Berger, J.; de Brauwere, N.; Doherty, O.; Harrison, A.; Fiedler, J.; Jones, C.; McDonnell, S.; McLean, A.; Nakonechny, L.; et al. Using the Five Domains Model to assess the adverse impacts of husbandry, veterinary, and equitation interventions on horse welfare. Animals 2018, 8, 41. [CrossRef]

23. Rowland, M.; Coombs, T.; Connor, M. A study of traveller horse owners' attitudes to horse care and welfare using an equine Body Condition Scoring system. Animals 2019, 9, 162. [CrossRef] [PubMed]

24. Hemsworth, L.M.; Jongman, E.; Coleman, G.J. Recreational horse welfare: The relationships between recreational horse owner attributes and recreational horse welfare. Appl. Anim. Behav. Sci. 2015, 165, 1-16. [CrossRef]

25. Hartmann, E.; Boe, K.E.; Christensen, J.; Hyyppä, S.; Jansson, H.; Jørgensen, G.; Ladewig, J.; Mejdell, C.; Norling, A.-Y.; Rundgren, M.; et al. A Nordic survey of management practices and owners attitudes towards keeping horses in groups. J. Anim. Sci. 2015, 93, 4564-4574. [CrossRef] [PubMed]

26. Hotzel, M.J.; Vieira, M.C.; Leme, D.P. Exploring horse owners' and caretakers' perceptions of emotions and associated behaviors in horses. J. Vet. Behav. Clin. Appl. Res. 2019, 29, 18-24. [CrossRef]

27. DuBois, C.; Nakonechny, L.; Derisoud, E.; Merkies, K. Examining Canadian equine industry participants' perceptions of horses and their welfare. Animals 2018, 8, 201. [CrossRef] [PubMed]

28. Bell, C.; Rogers, S.; Taylor, J.; Busby, D. Improving the recognition of equine affective states. Animals 2019, 9, 1124. [CrossRef]

29. Thompson, K.R.; Clarkson, L.; Riley, C.B.; van den Berg, M. Horse husbandry and preventive health practices in Australia: An online survey of horse guardians. J. Appl. Anim. Welf. Sci. 2018, 21, 347-361. [CrossRef]

30. McGowan, T.W.; Pinchbeck, G.; Phillips, C.J.C.; Perkins, N.; Hodgson, D.R.; McGowan, C.M. A survey of aged horses in Queensland, Australia. Part 2: Clinical signs and owners' perceptions of health and welfare. Austr. Vet. J. 2010, 88, 465-471. [CrossRef]

31. Owers, R. Should we slaughter horses at abattoirs? Vet. Rec. 2019, 185, 577. [CrossRef]

32. Bjornsdottir, S.; Frey, R.; Kristjansson, T.; Lundstrom, T. Bit-related lesions in Icelandic competition horses. Acta Vet. Scand. 2014, 56, 40. [CrossRef]

33. Zebisch, A.; May, A.; Reese, S.; Gehlen, H. The effect of different head-neck positions on physical and psychological stress parameters in the ridden horse. J. Anim. Phys. Anim. Nutr. 2014, 98, 901-907. [CrossRef] [PubMed]

34. Wyse, C.A.; McNie, K.A.; Tannahil, V.J.; Murray, J.K.; Love, S. Prevalence of obesity in riding horses in Scotland. Vet. Rec. 2008, 162, 590-591. [CrossRef] [PubMed]

35. Robin, C.A.; Ireland, J.L.; Wylie, C.E.; Collins, S.N.; Verheyen, K.L.P.; Newton, J.R. Prevalence of and risk factors for equine obesity in Great Britain based on owner-reported body condition scores. Equine Vet. J. 2015, 47, 196-201. [CrossRef] [PubMed]

36. Jaqueth, A.L.; Iwaniuk, M.E.; Burk, A.O. Characterization of the prevalence and management of over-conditioned ponies and horses in Maryland. J. Equine Vet. Sci. 2018, 68, 26-32. [CrossRef]

37. Yngvesson, J.; Rey Torres, J.C.; Lindholm, J.; Pattiniemi, A.; Andersson, P.; Sasser, H. Health and body conditions of riding school horses housed in groups or kept in conventional tie stall/box housing. Animals 2019, 9, 73. [CrossRef]

38. Frank, N.; Geor, R.J.; Bailey, S.R.; Durham, A.E.; Johnson, P.J. Equine metabolic syndrome. J. Vet. Int. Med. 2010, 24, 467-475. [CrossRef]

39. McGregor Argo, C. Appraising the portly pony: Body condition score and adiposity. Vet. Rec. 2009, 179, 158-160. [CrossRef]

40. Ireland, J.L.; Clegg, P.D.; McGowan, C.M.; McKane, S.A.; Chandler, K.J.; Pinchbeck, G.L. Disease prevalence in geriatric horses in the United Kingdom: Veterinary clinical assessment of 200 cases. Equine Vet. J. 2012, 44, 101-106. [CrossRef] 
41. Dalla Costa, E.; Murray, L.; Dai, F.; Canali, E.; Minero, M. Equine on-farm welfare assessment: A review of animal-based indicators. Anim. Welf. 2014, 23, 323-341. [CrossRef]

42. Verbeek, E.; Waas, J.R.; McLeay, L.; Matthews, L.R. Measurement of feeding motivation in sheep and the effects of feed restriction. Appl. Anim. Behav. Sci. 2011, 132, 121-130. [CrossRef]

43. Murray, M.J.; Eichorn, F.S. Effects of intermittent feed deprivation, intermittent feed deprivation with ranitidine administration and stall confinement with ad libitum access to hay on gastric ulceration in horses. Am. J. Vet. Res. 1996, 11, 1599-1603.

44. Nicol, C. Understanding equine stereotypies. Equine Vet. J. Suppl. 1999, 28, 20-25. [CrossRef] [PubMed]

45. Boyd, L.E.; Carbonaro, D.A.; Houpt, K.A. The 24-hour time budget of Przewalski horses. Appl. Anim. Behav. Sci. 1988, 21, 5-17. [CrossRef]

46. Wylie, C.E.; Ireland, J.L.; Collins, S.N.; Verheyen, K.L.P.; Newton, J.R. Demographics and management practices of horses and ponies in Great Britain: A cross-sectional study. Res. Vet. Sci. 2013, 95, 410-417. [CrossRef]

47. Hartmann, E.; SØndergaard, E.; Keeling, L. Keeping horses in groups: A review. Appl. Anim. Behav. Sci. 2012, 136, 77-87. [CrossRef]

48. Sondergaard, E.; Jensen, M.B.; Nicol, C.J. Motivation for social contact in horses measured by operant conditioning. Appl. Anim. Behav. Sci. 2011, 132, 131-137. [CrossRef]

49. Sarrafchi, A.; Blokhuis, H.J. Equine stereotypic behaviour: Causation, occurrence, and prevention. J. Vet. Behav. 2013, 8, 386-394. [CrossRef]

50. Thompson, K.R.; Clarkson, L.; Riley, C.B.; van den Berg, M. Horse-keeping practices in Australia: Findings from a national online survey of horse owners. Aust. Vet. J. 2017, 95, 437-443. [CrossRef]

51. Rioja-Lang, F.; Bacon, H.J.; Connor, M.; Dwyer, C.M. Determining priority welfare issues for cats in the United Kingdom using expert consensus. Vet. Rec. Open 2019, 6, e000365. [CrossRef]

52. Bennett, R.M.; Broom, D.M.; Henson, S.J.; Blaney, R.J.P.; Harper, G. Assessment of the impact of government animal welfare policy on farm animal welfare in the UK. Anim. Welf. 2004, 13, 1-11.

53. Buckland, E.L.; Corr, S.A.; Abeyesinghe, S.M.; Wathes, C.M. Prioritisiation of companion dog welfare issues using expert consensus. Anim. Welf. 2014, 23, 39-46. [CrossRef]

(C) 2020 by the authors. Licensee MDPI, Basel, Switzerland. This article is an open access article distributed under the terms and conditions of the Creative Commons Attribution (CC BY) license (http://creativecommons.org/licenses/by/4.0/). 